6. Veber B, Gachot B, Bedos JP, Wolff M. Severe sepsis after intravenous injection of contaminated propofol. Anesthesiology 1994;80:712-713.

7. Bennet SN, McNeil MM, Bland LA, et al. Postoperative infections traced to contamination of an intravenous anaesthetic, propofol. N Engl J Med 1995;333:147-154.

8. Wachowski I, Jolly DT, Hrazdil J, Galbraith JC, Greacen M, Clanachan AS. The growth of microorganisms in propofol and mixtures of propofol and lidocaine. Anesth Analg 1999;88:209_ 212.

9. O'Donnell NG, McSharry CP, Wilkinson PC, Asbury AJ. Comparison of the inhibitory effect of propofol, thiopentone and midazolam on neutrophil polarization in vitro in the presence or absence of human serum albumin. Br J Anaesth 1992;69:7074 .

10. El-Ebiary M, Torres A, Ramirez J, Xaubet A, Rodriguez-Roisin R. Lipid deposition during the long-term infusion of propofol. Crit Care Med 1995;23:1928-1930.

\section{Implementation of a Restricted Foods Policy at a Large Academic Medical Center}

To the Editor-Despite well-established safe food handling practices, foodborne illness remains a significant source of morbidity and mortality in the United States. Immunocompromised hospitalized patients are at increased risk of developing severe complications of foodborne illness. We describe the development and implementation of a restricted foods policy to minimize the risk of foodborne illness in vulnerable patients.

Foodborne illness represents a major source of morbidity and mortality in the United States, with an estimated 9.4 million episodes annually, including 55,961 hospitalizations and 1,351 deaths each year. ${ }^{1}$ Hospitals provide care for the most medically vulnerable and immunocompromised individuals in society; however, despite governmental safety regulations and well-established safe food handling practices, foodborne outbreaks in healthcare settings do occur and are associated with an increased risk of death compared with other settings. ${ }^{2}$

Listeria monocytogenes is uniquely suited to cause serious nosocomial infections, given its tendency to contaminate certain ready-to-eat food products, ability to replicate at refrigerator temperatures, and propensity to cause invasive infection in immunocompromised patients and pregnant women. Stem-cell/solid-organ transplant patients have a 2,584-fold greater risk than the general population of developing serious illness from L. monocytogenes infection, while patients with hematologic malignancy, HIV/AIDS, end-stage renal disease, diabetes, alcoholism, and age greater than 65 years have risks of developing serious illness from Listeria that range from 7.5 to 1,384 over that of the general population. ${ }^{3}$ Numerous outbreaks of nosocomial listeriosis have been reported, with hospital-provided sandwiches, ready-to-eat sausage products, diced celery, soft cheeses, and sliced deli meats most frequently implicated as the source of the outbreaks. ${ }^{2,-7}$ High mortality rates have been reported in these outbreaks, and most patients who died had some level of compromised immunity.

Despite the potentially catastrophic outcomes of listeriosis in immunocompromised patients, a survey of New York City acute care hospitals found that most hospitals allowed cold prepared salads (eg, tuna or chicken salad) and ready-to-eat deli meats to be served to immunocompromised patients, including pregnant women, transplant recipients, patients with hematologic malignancy, patients receiving chemotherapy, and those with chronic kidney or liver disease. ${ }^{8}$ Similarly, $14 \%-45 \%$ of New York City hospitals permitted soft cheeses to be served to patients with varying immunocompromising conditions. $^{8}$ Reports of healthcare-associated listeriosis prompted an evaluation of foods served to our hospitalized patients and the development and implementation of a restricted foods policy at our institution.

New York University Langone Medical Center (NYULMC) is a 705-bed academic tertiary referral center located in New York City that includes 63 intensive care unit beds, a 22-bed oncology unit, and a dedicated 6-bed bone marrow transplant unit. NYULMC performs approximately 75 solid-organ transplantations and 40 hematopoietic stem-cell transplantations annually. Our diverse patient population presented logistical challenges in implementing a restricted foods policy that targeted only specific immunocompromised patients. All patient food at NYULMC originates from the same location within our facility, and the constraints of our kitchen design rendered impossible the establishment of dedicated storage and preparation areas for foods destined for immunocompromised patients. While some institutions employ "low-bacteria" or "neutropenic" diets for their most immunocompromised patients, we chose to focus on food entry into our institution rather than distribution of food to specific patient populations, as many studies have called into question the benefit of these diets in the severely immunosuppressed.

To reduce the risk of listeriosis and other foodborne illnesses, we developed and implemented a restricted foods policy that applies to patients in our institution. Table 1 highlights foods that are not permitted to be served to any patient at NYULMC, pathogens of concern with these foods, and acceptable food alternatives that have lower potential for causing foodborne illness. In addition, to reduce the risk of waterborne pathogen exposure, only bottled water filtered by reverse osmosis, bottled/canned drinks that do not require refrigeration before opening, and pasteurized juices are served to our solid-organ and stem-cell transplant recipients and to patients undergoing induction chemotherapy for hematologic malignancies. Tap water, either alone or when added to other 
TABLE 1. Restricted Foods at New York University Langone Medical Center, Pathogens of Concern, and Acceptable Food Alternatives

\begin{tabular}{|c|c|c|c|}
\hline Food group & Unacceptable foods & Pathogens of concern & Acceptable alternatives \\
\hline Dairy & $\begin{array}{l}\text { Nonpasteurized or raw milk } \\
\text { Cheeses containing uncooked vegetables } \\
\text { Cheeses with molds (bleu, Stilton, Roque- } \\
\text { fort, Gorgonzola) }\end{array}$ & $\begin{array}{l}\text { Listeria monocytogenes } \\
\text { Salmonella enteritidis } \\
\text { Escherichia coli }\end{array}$ & $\begin{array}{l}\text { Pasteurized milk and milk products } \\
\text { Commercially packaged hard and semisoft } \\
\text { cheeses (cheddar, mozzarella, etc) }\end{array}$ \\
\hline Meat & $\begin{array}{l}\text { Raw or undercooked meat, poultry, fish, } \\
\text { game, tofu } \\
\text { Raw or undercooked eggs, nonpasteurized } \\
\text { egg substitutes (including certain prepa- } \\
\text { rations of hollandaise sauce and Caesar } \\
\text { dressing) } \\
\text { Raw or undercooked seafood } \\
\text { Deli-style ready-to-eat meats and poultry } \\
\text { Uncooked hot dogs or sausage } \\
\text { Uncooked smoked seafood (salmon/lox) } \\
\text { Tempeh products }\end{array}$ & $\begin{array}{l}\text { E. coli } \mathrm{O} 157: \mathrm{H} 7 \\
\text { S. enteritidis } \\
\text { Campylobacter jejuni } \\
\text { Clostridium perfringens } \\
\text { Toxoplasma gondii } \\
\text { Vibrio spp. } \\
\text { L. monocytogenes }\end{array}$ & $\begin{array}{l}\text { Well-done meats, cooked to safe minimum } \\
\text { cooking temperatures } \\
\text { Eggs cooked until both white and yolk are } \\
\text { firm } \\
\text { Canned meats } \\
\text { Pasteurized eggs and egg substitutes } \\
\text { Cooked hot dogs or sausage } \\
\text { Refrigerated smoked seafood if cooked to } \\
160^{\circ} \mathrm{F}\end{array}$ \\
\hline Fruits and nuts & $\begin{array}{l}\text { Unwashed raw fruits } \\
\text { Nonpasteurized fruit and vegetable juices } \\
\text { Fresh fruit salsas } \\
\text { Unroasted raw nuts or nuts in shells }\end{array}$ & $\begin{array}{l}\text { E. coli } \mathrm{O} 157: \mathrm{H7} \\
\text { S. enteritidis } \\
\text { Norovirus } \\
\text { Hepatitis A virus } \\
\text { Shigella } \\
\text { Cryptosporidium } \\
\text { Giardia }\end{array}$ & $\begin{array}{l}\text { Well-washed raw and frozen fruit } \\
\text { Cooked, canned, and frozen fruit } \\
\text { Pasteurized juices and frozen juice } \\
\text { concentrates } \\
\text { Dried fruits } \\
\text { Canned or bottled roasted nuts } \\
\text { Commercially packaged nut butters }\end{array}$ \\
\hline Vegetables and soups & $\begin{array}{l}\text { Unwashed raw vegetables or herbs } \\
\text { Fresh, nonpasteurized vegetable salsa } \\
\text { Raw vegetable sprouts (alfalfa, clover, etc) } \\
\text { Salads } \\
\text { Miso products (soups, paste) }\end{array}$ & $\begin{array}{l}\text { E. coli } \mathrm{O} 157: \mathrm{H7} \\
\text { S. enteritidis } \\
\text { Norovirus } \\
\text { Hepatitis A virus } \\
\text { Shigella } \\
\text { Cryptosporidium } \\
\text { Giardia }\end{array}$ & $\begin{array}{l}\text { Well-washed raw and frozen vegetables } \\
\text { Cooked fresh/frozen/canned vegetables } \\
\text { Shelf-stable bottled salsa } \\
\text { Cooked vegetable sprouts } \\
\text { Fresh, well-washed herbs and dry herbs } \\
\quad \text { used in cooked foods }\end{array}$ \\
\hline
\end{tabular}

NOTE. Adapted from Tomblyn et al. ${ }^{9}$

items for reconstitution, is not permitted in these high-risk patients.

Scientific guidelines, governmental recommendations, and published literature, including from the transplant community, were reviewed to help guide this policy. ${ }^{910}$ Unfortunately, robust evidence-based guidelines specifying appropriate food restrictions in hospital settings are lacking. Although improved presentation and variety of hospital-supplied food can benefit a patient's well-being and perception of care, the risk of foodborne illness in hospitalized patients is often underappreciated, and pressures to improve patient satisfaction scores may inadvertently lead to unsafe foods on the hospital menu. Clear guidelines are needed to ensure patient safety, and we hope the publication of our policy will serve as the beginning of a reevaluation of food safety in healthcare settings.

\section{ACKNOWLEDGMENTS}

Potential conflicts of interest. All authors report no conflicts of interest relevant to this article. All authors submitted the ICMJE Form for Disclosure of Potential Conflicts of Interest, and the conflicts that the editors consider relevant to this article are disclosed here.

\section{Scott R. Cutro, MD; ${ }^{1,2, a}$ Ranekka Dean, MPA, RN; ${ }^{2}$ Michael S. Phillips, $\mathrm{MD}^{1,2}$}

Affiliations: 1. Division of Infectious Diseases, New York University School of Medicine, New York, New York; 2. Department of Infection Prevention and Control, New York University Langone Medical Center, New York, New York.

Address correspondence to Michael S. Phillips, MD, Greenberg Hall (Room SC-132), 545 First Avenue, New York, NY 20016 (michael .phillips@nyumc.org). 
a Present affiliation: The Southeast Permanente Medical Group, Atlanta, Georgia.

Infect Control Hosp Epidemiol 2014;35(6):749-751

(C) 2014 by The Society for Healthcare Epidemiology of America. All rights reserved. 0899-823X/2014/3506-0025\$15.00. DOI: $10.1086 / 676439$

\section{REFERENCES}

1. Scallan E, Hoekstra RM, Angulo FJ, et al. Foodborne illness acquired in the United States-major pathogens. Emerg Infect Dis 2011;17(1):7-15.

2. Centers for Disease Control and Prevention. Vital signs: Listeria illnesses, deaths, and outbreaks_-United States, 2009-2011. MMWR Morb Mortal Wkly Rep 2013;62(22):448-452.

3. World Health Organization, Food and Agriculture Organization of the United Nations. Risk Assessment of Listeria monocytog enes in Ready-To-Eat Foods. Microbiological risk assessment series 4. 2004. http://www.who.int/foodsafety/publications/micro /en/mra4.pdf. Accessed May 2, 2013.

4. Gaul LK, Farag NH, Shim T, Kingsley MA, Silk BJ, Hyytia-Trees E. Hospital-acquired listeriosis outbreak caused by contaminated diced celery-Texas, 2010. Clin Infect Dis 2013;56(1):2026.

5. Little CL, Amar CF, Awofisayo A, Grant KA. Hospital-acquired listeriosis associated with sandwiches in the UK: a cause for concern. J Hosp Infect 2012;82(1):13-18.

6. Winter $\mathrm{CH}$, Brockmann SO, Sonnentag SR, et al. Prolonged hospital and community-based listeriosis outbreak caused by ready-to-eat scalded sausages. J Hosp Infect 2009;73(2):121-128.

7. Johnsen BO, Lingaas E, Torfoss D, Strom EH, Nordoy I. A large outbreak of Listeria monocytogenes infection with short incubation period in a tertiary care hospital. J Hosp Infect 2010; 61(6):465-470.

8. Cokes C, France AM, Reddy V, et al. Serving high-risk foods in a high-risk setting: survey of hospital food service practices after an outbreak of listeriosis in a hospital. Infect Control Hosp Epidemiol 2011;32(4):380-386.

9. Tomblyn M, Chiller T, Einsele H, et al. Guidelines for preventing infectious complications among hematopoietic cell transplantation recipients: a global perspective. Biol Blood Marrow Transplant 2009;15(10):1143-1238.

10. Lund BM, O'Brien SJ. Microbiological safety of food in hospitals and other healthcare settings. J Hosp Infect 2009;73(2):109-120.

\section{Heteroresistance to Carbapenems in New Delhi Metallo- $\beta$-Lactamase-1-Producing Isolates: A Challenge for Detection?}

To the Editor-The worldwide dissemination of bacteria producing New Delhi metallo- $\beta$-lactamase (NDM) is a major public health concern owing to its worldwide dissemination. NDM-1 has now been detected in some South American countries, including Brazil. ${ }^{1}$

The first Brazilian NDM-1-producing isolate was a Providencia rettgeri isolate that had an unexpected susceptibility profile, with susceptibility to ertapenem (minimum inhibitory concentration $[\mathrm{MIC}], 0.5 \mathrm{mg} / \mathrm{L}$ ) and meropenem (MIC, $0.75 \mathrm{mg} / \mathrm{L}$ ) and only a low-level resistance to imipenem (MIC, $4 \mathrm{mg} / \mathrm{L}$ ) by epsilometer test (E-test); ${ }^{1}$ the latter finding might be expected since higher imipenem MICs are common to wild-type Providencia spp.

The susceptibility of the Brazilian P. rettgeri was reassessed by broth microdilution, showing similar MICs to those previously reported by E-test: $0.25,0.5$, and $8.0 \mathrm{mg} / \mathrm{L}$ for ertapenem, meropenem, and imipenem, respectively. Considering such an unusual susceptibility profile, a population analysis profile (PAP) was performed to detect the presence of possible ertapenem- and meropenem-heteroresistant subpopulations. ${ }^{2}$ Briefly, a $20-\mu \mathrm{L}$ aliquot from a $24-\mathrm{h}$ culture serially diluted in saline with approximately $10^{8}$ bacterial colony forming units was spread on Mueller-Hinton agar plates containing $0,0.125,0.25,0.5,1,2,3,4$, and $6 \mathrm{mg} / \mathrm{L}$ of meropenem and ertapenem. Colonies were counted after $48 \mathrm{~h}$ of incubation at $35^{\circ} \mathrm{C}$.

The PAP experiments revealed the growth of colonies up to the concentrations of 0.5 and $2 \mathrm{mg} / \mathrm{L}$ of ertapenem and meropenem, respectively. However, the MICs of ertapenem and meropenem of these subpopulations were greater than $32 \mathrm{mg} / \mathrm{L}$ for both carbapenems, and the same elevated MICs were observed after daily subculture in antibiotic-free medium for 4 days.

We report an ertapenem- and meropenem-susceptible NDM-1-producing $P$. rettgeri harboring subpopulations highly resistant to both drugs by PAP. Interestingly, there was no subpopulation growth in plates with ertapenem and meropenem concentrations greater than 0.5 and $2.0 \mathrm{mg} / \mathrm{L}$, respectively; nonetheless, when MICs of these colonies were performed, high-level resistance was demonstrated. An ertapenem-susceptible NDM-1-producing $P$. rettgeri has also been previously reported in Israel, but no experiment for heteroresistance was performed for that isolate. ${ }^{3}$

Although other carbapenemase-producing isolates have shown heteroresistance to carbapenems, ${ }^{2,4,5}$ to our knowledge, this is the first description of an NDM-1-producing Enterobacteriaceae with such a resistance profile. Beyond the potential clinical impact of heteroresistance to carbapenems, this finding has important epidemiological consequences. From an infection control perspective, if this isolate had not demonstrated resistance to imipenem, it would have been managed as another carbapenem-susceptible Enterobacteriaceae. Infection control measures would not have been implemented, nor would the presence of NDM-1 have been detected, potentially contributing to further spread of this resistance mechanism.

In summary, we showed that an isolate carrying the $b l a_{\mathrm{NDM}-1}$ gene might seemly demonstrate susceptibility to carbapenems, including ertapenem, by conventional methods. NDM-1-producing isolates may actually harbor subpopulations detected only by PAP experiments. The prevalence of 